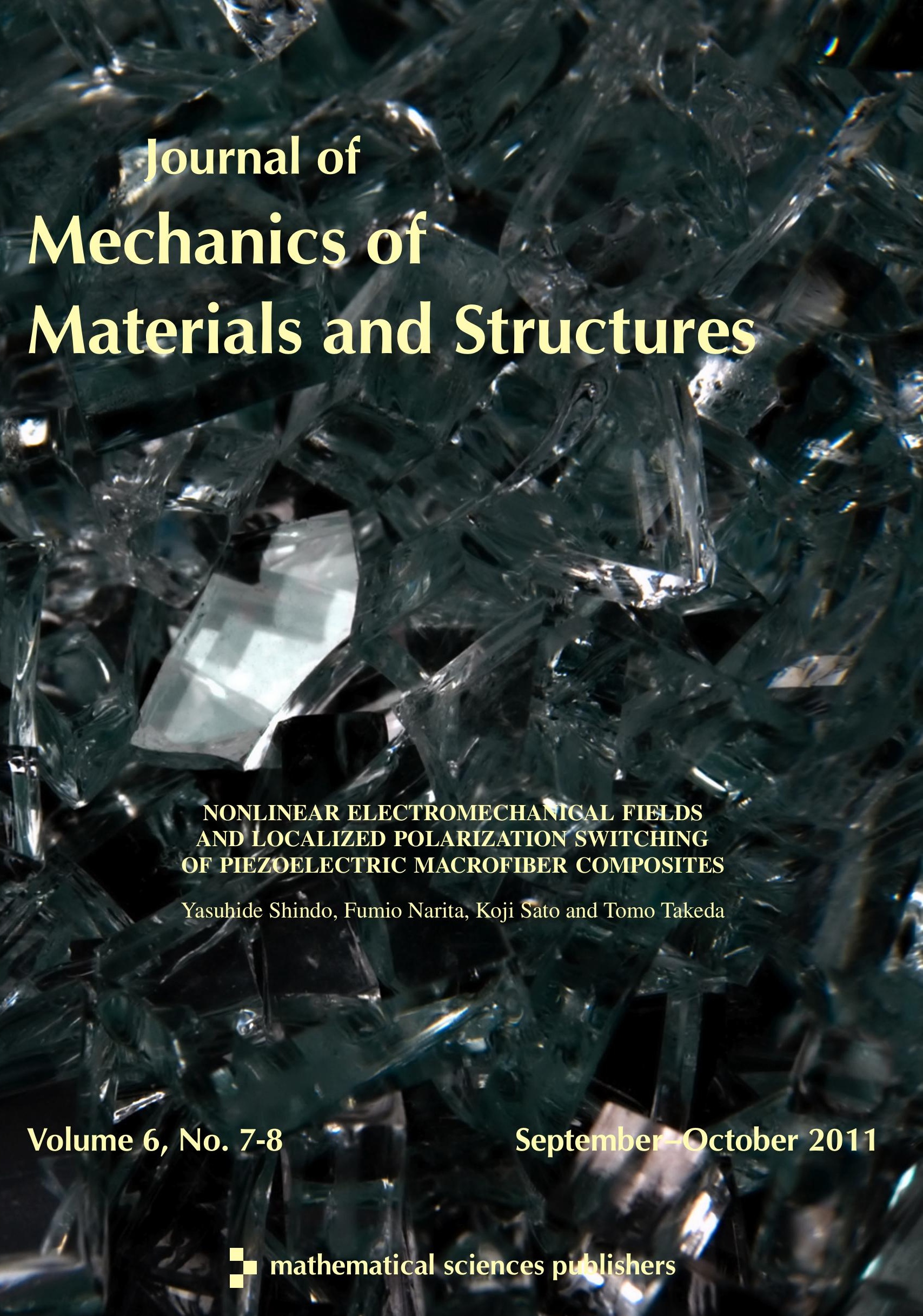




\title{
NONLINEAR ELECTROMECHANICAL FIELDS AND LOCALIZED POLARIZATION SWITCHING OF PIEZOELECTRIC MACROFIBER COMPOSITES
}

\author{
Yasuhide Shindo, Fumio Narita, Koji Sato and Tomo Takeda
}

\begin{abstract}
This paper examines theoretically and experimentally the nonlinear electromechanical response of piezoelectric macrofiber composites. 3D finite element analysis was carried out to study the strain versus electric field curve and the internal electromechanical fields near interdigitated electrodes in the macrofiber composites by introducing a model for polarization switching. The piezoelectric fibers in the macrofiber composite are partially or fully poled. Results on the strain versus electric field curves from microelectromechanical models and simple experiments were also presented, and comparison was made with the finite element solutions.
\end{abstract}

\section{Introduction}

Piezoelectric macrofiber composite (MFC) elements, developed at NASA Langley Research Center for aerospace applications, are gaining increasing interest for applications in structural health monitoring [Brunner et al. 2009] and energy harvesting [Song et al. 2009] systems. The development of the MFC helps to overcome some of the limitations of conventional lead zirconate titanate (PZT) ceramics, especially brittleness, lack of reliability, and conformability. In [Williams et al. 2006] the actuation behavior of MFC under electromechanical loading was investigated analytically and experimentally, and the piezoelectric and electrostrictive coefficients were discussed. Also, in [Bilgen et al. 2010] the structural response of MFC actuated clamped-free thin cantilever beams was studied.

In some MFC applications, high values of stress and electric fields arise in the neighborhood of electrode tips in PZT fibers, and the field concentrations can result in electromechanical degradation [Shindo et al. 2004; Narita et al. 2007]. There is also another problem related to the manufacturing process. A PZT wafer is first diced into rectangular fibers. This fiber arrangement is infiltrated with resin and cured together with interdigitated Kapton electrode sheets in a high-precision lamination pressing machine. After this, in a final step, the MFC is polarized with high voltages for about 10 minutes at room temperature. With these fabrication techniques, the resulting polarization of the PZT fibers will inevitably be partial. Due to the presence of interdigitated electrode (IDE) edges and the resulting inhomogeneity of the constituents, piezoelectric MFCs can suffer damage prematurely during service. It is therefore important to understand electromechanical field concentrations near IDEs in piezoelectric MFCs.

In this paper, we investigate the electromechanical response of piezoelectric MFCs. Recent works [Dano and Jullière 2007; Deraemaeker et al. 2009] used the linear constitutive relations for coupling

The authors thank Smart Material Corp. for providing useful information regarding piezoelectric MFCs.

Keywords: piezomechanics, finite element method, material testing, piezoelectric composites, electromechanical field concentrations, smart materials and structures. 
response in MFCs; hence the novelty of this work consists of exploration of the nonlinear behavior during the polarization switching process and comparison of the numerical values with the experimental data. In Section 2, the basic equations for piezoelectric materials are described. A nonlinear 3D finite element model incorporating the polarization switching mechanism is also presented to predict the strain versus electric field curve and internal electromechanical fields near IDEs in piezoelectric MFCs. The piezoelectric fibers in the MFC are partially or fully poled. In addition, the effective longitudinal piezoelectric constant of the MFC with fully poled PZT fibers is derived analytically using microelectromechanical models. In Section 3, the electric field-induced strain is measured. Test results on the strain versus electric field curve are compared to predictions in Section 4. The finite element results on the internal electromechanical fields are then discussed. Our conclusions are summarized in Section 5.

\section{Analysis}

2.1. Basic equations. Consider a piezoelectric material with no body force and free charge. The governing equations in the Cartesian coordinates $x_{i}(i=1,2,3)$ are

$$
\sigma_{j i, j}=0, \quad D_{i, i}=0,
$$

where $\sigma_{i j}$ is the stress tensor, $D_{i}$ is the electric displacement vector, a comma denotes partial differentiation with respect to the coordinate $x_{i}$, and Einstein summation convention over repeated indices is used. The relation between the strain tensor $\varepsilon_{i j}$ and the displacement vector $u_{i}$ is given by

$$
\varepsilon_{i j}=\frac{1}{2}\left(u_{j, i}+u_{i, j}\right),
$$

and the electric field intensity vector is $E_{i}=-\phi_{, i}$, where $\phi$ is the electric potential. In a ferroelectric material, domain switching leads to changes in the remanent strain $\varepsilon_{i j}^{\mathrm{r}}$ and remanent polarization $P_{i}^{\mathrm{r}}$. The constitutive relations can be written as

$$
\sigma_{i j}=c_{i j k l}\left(\varepsilon_{k l}-\varepsilon_{k l}^{\mathrm{r}}\right)-e_{k i j} E_{k}, \quad D_{i}=e_{i k l}\left(\varepsilon_{k l}-\varepsilon_{k l}^{\mathrm{r}}\right)+\epsilon_{i k} E_{k}+P_{i}^{\mathrm{r}} .
$$

In (3), $c_{i j k l}$ and $e_{i k l}$ are the elastic and piezoelectric tensors, and $\epsilon_{i k}$ is the dielectric permittivity tensor. Valid symmetry conditions for the material constants are

$$
c_{i j k l}=c_{j i k l}=c_{i j l k}=c_{k l i j}, \quad e_{k i j}=e_{k j i}, \quad \epsilon_{i k}=\epsilon_{k i} .
$$

The constitutive equations (3) for piezoelectric material poled in the $x_{3}$-direction are found in Appendix A.

Although there are many criteria that can be used to predict polarization switching in piezoelectric materials, we choose the switching criterion proposed in [Hwang et al. 1995]. This is due to the fact that the model is simple and quite successful at predicting the homogeneous average response of PZT material systems [Steinkopff 1999; Hayashi et al. 2003]. In this model, the direction of a spontaneous polarization $P^{\mathrm{s}}$ of each grain can change by $90^{\circ}$ or $180^{\circ}$ for ferroelectric switching induced by a sufficiently large electric field. $90^{\circ}$ ferroelastic switching is induced by a sufficiently large stress field. This criterion requires that a polarization switches when the combined electrical and mechanical work exceeds a critical value; that is,

$$
\sigma_{i j} \Delta \varepsilon_{i j}+E_{i} \Delta P_{i} \geq 2 P^{\mathrm{s}} E_{\mathrm{c}},
$$


where $E_{c}$ is a coercive electric field, and $\Delta \varepsilon_{i j}$ and $\Delta P_{i}$ are the changes in the spontaneous strain and spontaneous polarization during switching, respectively. The values of $\Delta \varepsilon_{i j}$ and $\Delta P_{i}$ are given in Appendix B. The constitutive equations (3) after polarization switching are given by

$$
\sigma_{i j}=c_{i j k l}\left(\varepsilon_{k l}-\varepsilon_{k l}^{\mathrm{r}}\right)-e_{k i j}^{\prime} E_{k}, \quad D_{i}=e_{i k l}^{\prime}\left(\varepsilon_{k l}-\varepsilon_{k l}^{\mathrm{r}}\right)+\epsilon_{i k} E_{k}+P_{i}^{\mathrm{r}} .
$$

The new piezoelectric constant $e_{i k l}^{\prime}$ is given in Appendix C.

2.2. Model. Consider a M-4010-P1 MFC (Smart Material Corp., Sarasota, FL) with overall dimensions of about $50 \mathrm{~mm} \times 22 \mathrm{~mm} \times 0.3 \mathrm{~mm}$. The MFC is comprised of very thin PZT-5A fibers (width $2 w_{\mathrm{p}}$, thickness $2 h_{\mathrm{p}}$ ) that are unidirectionally aligned in an epoxy matrix and sandwiched between two sets of copper IDE (width $2 w_{\mathrm{e}}$, thickness $h_{\mathrm{e}}$ ) patterns as shown in Figure 1a. The IDE patterns are printed on a Kapton film (thickness $h_{\mathrm{k}}$ ). The MFC has an IDE spacing of about $0.5 \mathrm{~mm}$ and has an active area of about $40 \mathrm{~mm} \times 10 \mathrm{~mm}$. The material characteristics of PZT-5A are listed in Table 1, and the coercive electric field is approximately $E_{\mathrm{c}}=1.5 \mathrm{MV} / \mathrm{m}$. The Young's modulus $E$ and Poisson's ratio $v$ of the epoxy, copper, and Kapton are listed in Table 2 [Deraemaeker et al. 2009].

Figure $1 \mathrm{~b}$ illustrates the repeating unit of the MFC. A rectangular Cartesian coordinate system O- $x y z$ is used with the $z$-axis coinciding with the PZT fiber direction. The repeating unit of the MFC occupies the region $(0 \leq x \leq W, 0 \leq y \leq H, 0 \leq z \leq L)$. The model consists of rectangular PZT fiber (width $w_{\mathrm{p}}$, length $L$ ) embedded in an epoxy matrix and Kapton film (width $W$, length $L$ ). Electrodes 1 and 3 of area $W \times w_{\mathrm{e}}$ and electrode 2 of area $W \times 2 w_{\mathrm{e}}$ are also incorporated into the model. The total thickness of the model is $H=h_{\mathrm{p}}+h_{\mathrm{e}}+h_{\mathrm{k}}$.

With the IDEs, the electric field $E_{0}$ is applied along the PZT fibers (the $z$-direction) which produces much higher in-plain actuation strain $\varepsilon_{0}$ than traditional monolithic PZT poled through-the-thickness (see Figure 2) [Bent and Hagood 1997; Williams et al. 2004; Paradies and Melnykowycz 2007]. We consider the following electrical boundary conditions: the electric potentials on the interface between the PZT fiber and electrode 1 (that is, $0 \leq x \leq w_{\mathrm{p}}, y=h_{\mathrm{p}}, 0 \leq z \leq w_{\mathrm{e}}$ ) and the interface between the PZT fiber and electrode 3 (that is, $\left.0 \leq x \leq w_{\mathrm{p}}, y=h_{\mathrm{p}}, L-w_{\mathrm{e}} \leq z \leq L\right)$ equal the applied voltage, $\phi=V_{0}$, and the interface between the PZT fiber and electrode 2 (that is, $0 \leq x \leq w_{\mathrm{p}}, y=h_{\mathrm{p}}, L / 2-w_{\mathrm{e}} \leq z \leq L / 2+w_{\mathrm{e}}$ ) is connected to the ground, so that $\phi=0$. The applied electric field $E_{0}$ can be estimated to be the voltage $V_{0}$

\begin{tabular}{|ccccccccccc|}
\hline & & \multicolumn{3}{c}{ Elastic stiffnesses } & \multicolumn{3}{c}{ Piezoelectric } & \multicolumn{2}{c}{ Dielectric constants } \\
& & \multicolumn{3}{c}{$\left(\times 10^{10} \mathrm{~N} / \mathrm{m}^{2}\right)$} & \multicolumn{4}{c}{ coefficients $\left(\mathrm{C} / \mathrm{m}^{2}\right)$} & $\left(\times 10^{-10} \mathrm{C} / \mathrm{V} \mathrm{m}\right)$ \\
& $c_{11}$ & $c_{33}$ & $c_{44}$ & $c_{12}$ & $c_{13}$ & $e_{31}$ & $e_{33}$ & $e_{15}$ & $\epsilon_{11}$ & $\epsilon_{33}$ \\
PZT-5A & 12.0 & 11.1 & 2.1 & 7.51 & 7.51 & -3.05 & 21.1 & 11.8 & 81.1 & 73.5 \\
\hline
\end{tabular}

Table 1. Material properties of PZT-5A fiber.

\begin{tabular}{|lcc|}
\hline & Young's modulus $E\left(\times 10^{10} \mathrm{~N} / \mathrm{m}^{2}\right)$ & Poisson's ratio $v$ \\
Epoxy & 0.29 & 0.30 \\
Copper & 11.7 & 0.31 \\
Kapton & 0.28 & 0.30 \\
\hline
\end{tabular}

Table 2. Material properties of nonpiezoelectric constituents. 


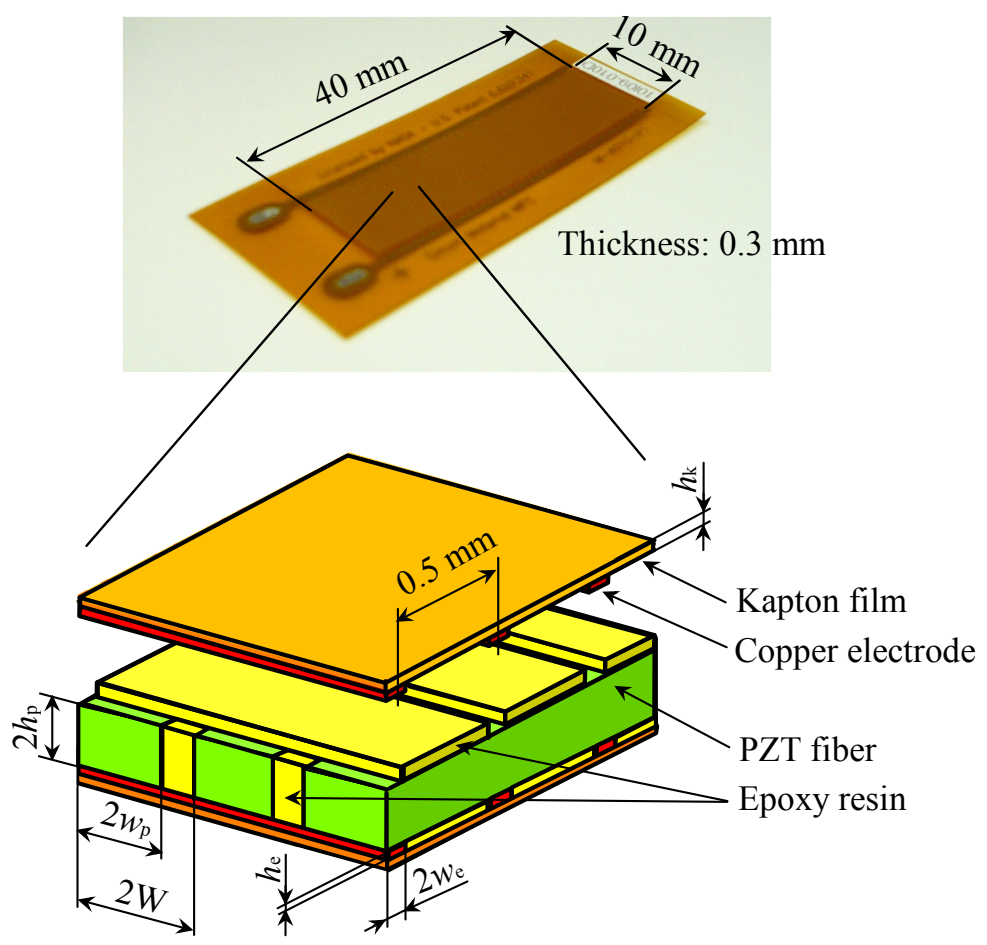

(a)

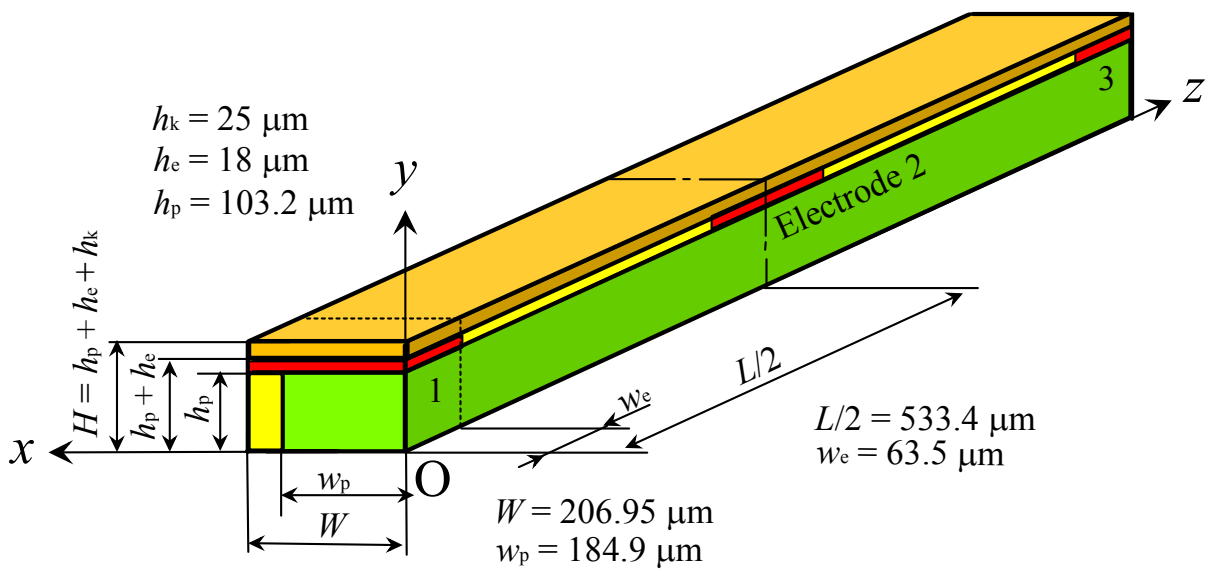

(b)

Figure 1. Schematic drawing of MFC: (a) lay-up and geometry and (b) repeating unit.

divided by the IDE spacing $L / 2$. The mechanical boundary conditions include the traction-free condition on the top surface at $y=H$ and the zero-displacement conditions on the $x=0, y=0$, and $z=0$ faces. Also included are the symmetry conditions on the side surfaces at $x=W$ and $z=L$.

Consider two types of poling. The first is partially poled. For partially poled PZT fibers, a matrix of crystalline grains with an idealized microstructure [Dent et al. 2007] is first considered, where each grain has a random polarization obtained using statistical procedures [Swain and Swain 1980]. The resulting 


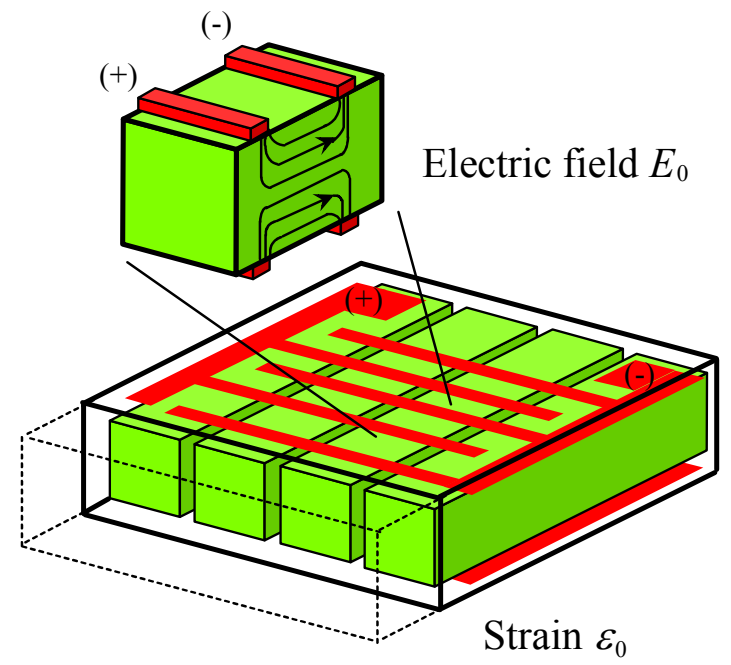

Figure 2. Strain and electric field of MFC with IDE.

material is equivalent to an unpoled piezoelectric [Shindo et al. 2009]. Figure 3a shows a typical model $(x=0$ plane) with a fine microstructure. The grain polarizations are quantized to just six orientations, corresponding to the two directions along the three principal axes. Other directions are not considered here for simplicity. High voltage is next applied through finite element analysis (FEA), and the PZT fiber model is partially polarized. The second has fully poled PZT fibers (see Figure $3 b$ ).

Each element consists of many grains, and each grain is modeled as a uniformly polarized cell that contains a single domain. The model neglects domain wall effects and interaction among different domains. In reality, this is not true, but the assumption does not affect the macroscopic behavior of the MFC. The polarization switching is defined for each element. The voltage $V_{0}$ is applied, and the

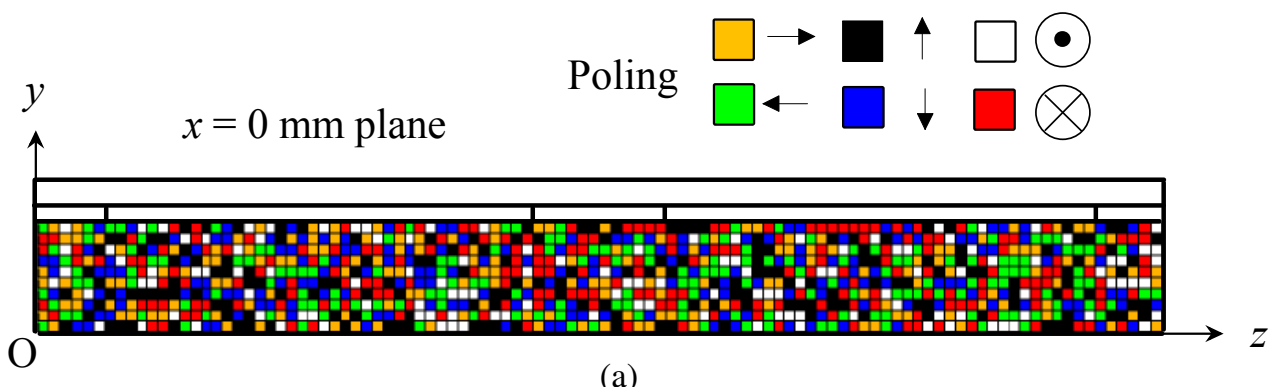

(a)

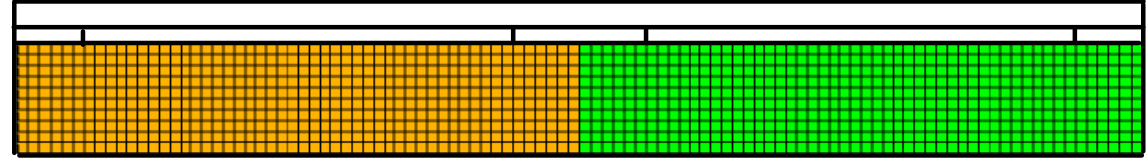

(b)

Figure 3. Models of (a) unpoled and (b) fully poled PZT fibers. 
electromechanical fields of each element are computed from the FEA. The switching criterion of (5) is checked for every element to see if switching will occur. After all possible polarization switches have occurred, the piezoelectricity tensor of each element is rotated to the new polarization direction. The electromechanical fields are recalculated, and the process is repeated until the solution converges. The macroscopic response of the MFC is determined by the finite element model.

The finite element computations by ANSYS were provided by modifying the program with routines developed in our previous work (for example, [Shindo et al. 2004]). The spontaneous polarization $P^{s}$ and strain $\gamma^{s}$ were assigned representative values of $0.3 \mathrm{C} / \mathrm{m}^{2}$ and 0.004 , respectively, based on the experimental data [Hwang et al. 1995]. Simulations were also run with the spontaneous polarization and strain values varying, though the results are not shown here since changing these values did not impact the results. Each element was defined by an eight-node 3D coupled field solid for the PZT fiber and an eight-node 3D structural solid for the epoxy matrix, Kapton film, and copper electrodes.

The strain $\varepsilon_{0}^{e}$ of the repeating unit for the fully poled PZT fiber under stress-free conditions is related to the electric field $E_{0}$ by the expression [Deraemaeker et al. 2009]:

$$
\varepsilon_{0}^{e}=d_{33}^{e} E_{0} .
$$

Here, the effective longitudinal piezoelectric coefficient $d_{33}^{e}$ is obtained, using microelectromechanics models based on the uniform field assumptions [Tan and Tong 2001]. Assuming that $90^{\circ}$ switching does not occur, the effective coefficient for the repeating unit without Kapton film or copper/epoxy layer is given by

$$
d_{33}^{e}= \begin{cases}e_{31}^{e} s_{13}^{e}+e_{32}^{e} s_{23}^{e}+e_{33}^{e} s_{33}^{e} & \text { if } E_{0}>-E_{c}, \\ -\left(e_{31}^{e} s_{13}^{e}+e_{32}^{e} s_{23}^{e}+e_{33}^{e} s_{33}^{e}\right) & \text { if } E_{0} \leq-E_{c},\end{cases}
$$

where $e_{31}^{e}, e_{32}^{e}, e_{33}^{e}, s_{13}^{e}, s_{23}^{e}$, and $s_{33}^{e}$ are given in Appendix D.

\section{Experimental procedure}

The free strain $(\varepsilon)$ response of the M-4010-P1 MFC (see Figure 1a) was measured. Strain gages were bonded symmetrically at the center of the active area on both sides of the piezoelectric MFC. Voltage was applied using a power supply for voltages up to $1.25 \mathrm{kV} / \mathrm{DC}$ in order to generate the strain versus electric field curve. A plot of applied voltage versus time during the test is shown in Figure 4. The MFC

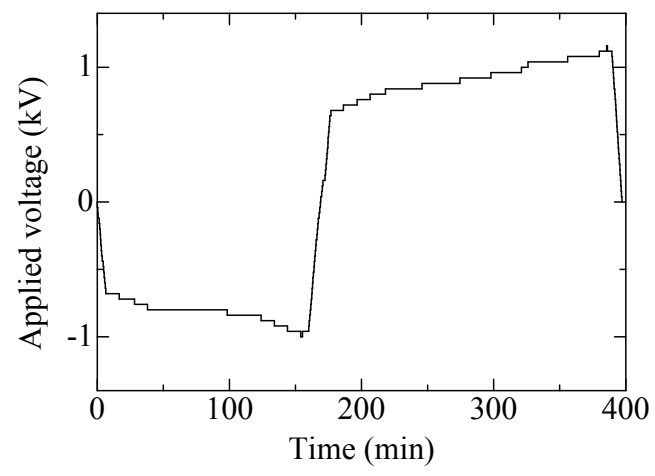

Figure 4. Applied voltage versus time. 
was then cut and observed using a digital microscope. The measured entities were statistically analyzed to obtain realistic geometrical parameters. The main values are represented in Figure 1b.

\section{Results and discussion}

Figure 5 shows the FEA results for the distribution of poled areas at the $x=0 \mathrm{~mm}$ plane for the PZT fiber under the electric field for $E_{0}=E_{\mathrm{c}}=1.5 \mathrm{MV} / \mathrm{m}$ and for $E_{0}=2 E_{\mathrm{c}}=3 \mathrm{MV} / \mathrm{m}$. The unpoled areas are observed under the coercive electric field. Moreover, at an electric field of $2 E_{\mathrm{c}}$, there are some areas where the pole is not aligned. Figure 6 provides the strain versus electric field for the piezoelectric MFCs. The solid and dot-dashed lines represent the strain $\varepsilon_{z z}$ at $x=0, y=H$, and $z=0$ for MFCs with partially and fully poled PZT fibers from the FEA while the open circle represents the test data $\varepsilon$. The partially poled PZT fiber is obtained under $E_{0}=2 E_{c}$ (see Figure $5 \mathrm{~b}$ ). Also shown is the analytical data $\varepsilon_{0}^{e}$ obtained from the microelectromechanics models (dashed line). The FEA results show that as the electric field $E_{0}$

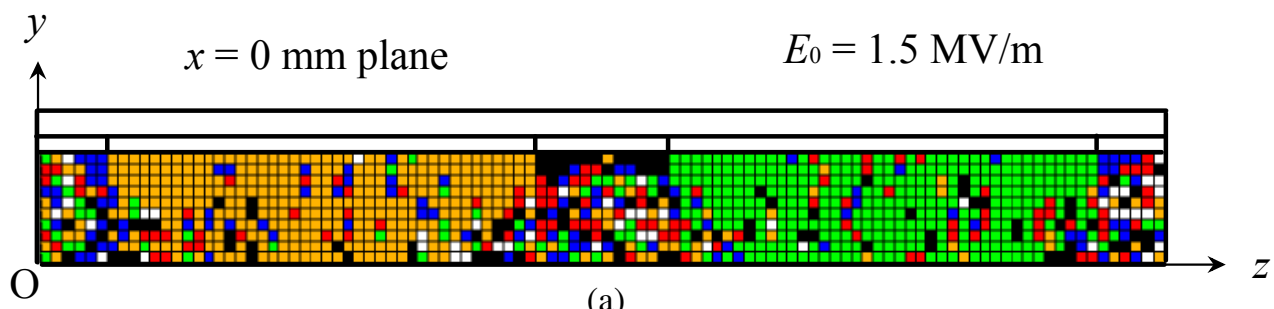

(a)

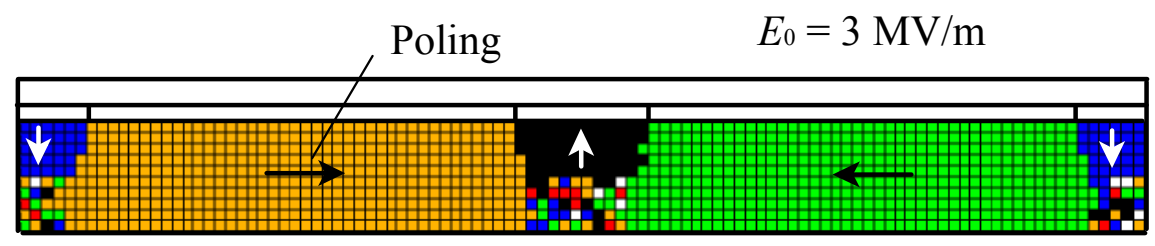

(b)

Figure 5. Images of poling for PZT fiber at (a) $E_{0}=E_{\mathrm{c}}=1.5 \mathrm{MV} / \mathrm{m}$ and (b) $E_{0}=2 E_{\mathrm{c}}=3 \mathrm{MV} / \mathrm{m}$.

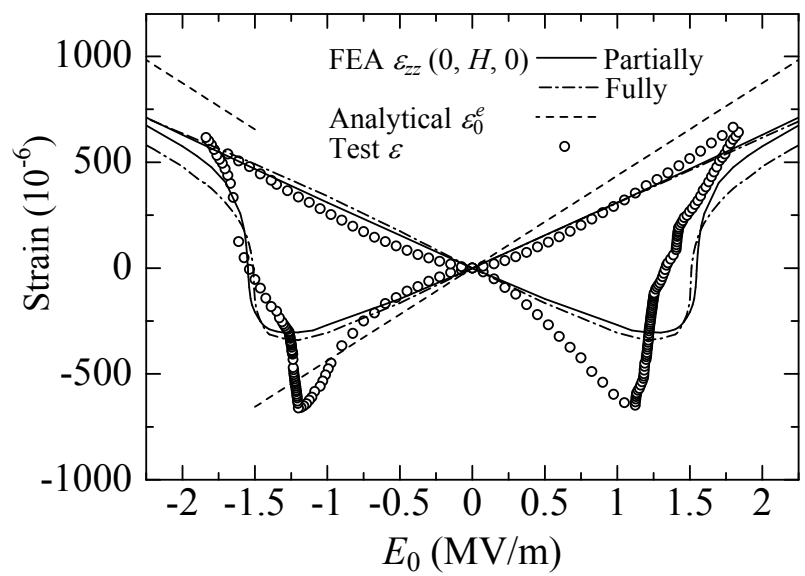

Figure 6. Strain versus electric field for piezoelectric MFCs. 


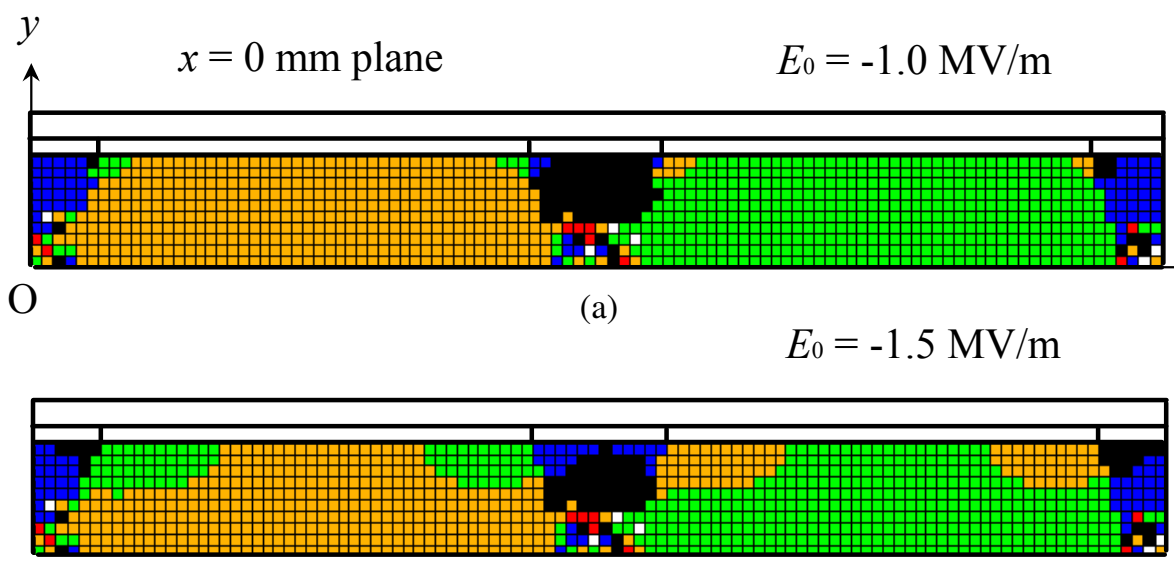

(b)

$$
E_{0}=-2.0 \mathrm{MV} / \mathrm{m}
$$

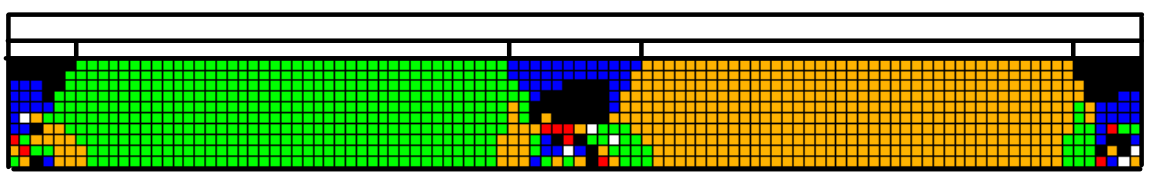

(c)

Figure 7. Polarization switching zone induced by electric field of (a) $E_{0}=-1.0 \mathrm{MV} / \mathrm{m}$, (b) $E_{0}=-1.5 \mathrm{MV} / \mathrm{m}$, and (c) $E_{0}=-2.0 \mathrm{MV} / \mathrm{m}$ at the $x=0 \mathrm{~mm}$ plane for MFC with partially poled PZT fibers.

is increased from zero initially, the tensile strain increases linearly due to the piezoelectric effect. On the other hand, the compressive strain increases nonlinearly as the electric field is lowered from zero; then, the compressive strain reaches maximum at about $E_{0}=-1.25 \mathrm{MV} / \mathrm{m}$ as localized depolarization occurs. The compressive strain then decreases, and the tensile strain rises as the negative remanent polarization develops. As polarization reversal takes place, the piezoelectric coefficients of the PZT fiber change their signs. This leads to a reversal of the macroscopic piezoelectric effect. The tensile strain decreases as the negative electric field is gradually decreased. As the electric field is cycled, the butterfly loop is repeated. Note that there is a good agreement between the FEA and the test. Also, little difference in the strain versus electric field curve is observed between the MFCs with partially and fully poled PZT fibers. Although the strain obtained from the microelectromechanics models is larger than that from the FEA due to neglecting the Kapton film and copper/epoxy layer, the microelectromechanics models may serve to predict roughly the strain response of the MFCs. Figure 7 shows the polarization switching zones at the $x=0 \mathrm{~mm}$ plane of the MFC with partially poled PZT fibers. The original poled state is shown in Figure $5 \mathrm{~b}$. Under the electric field, $E_{0}=-1.0 \mathrm{MV} / \mathrm{m}$, below the coercive field strength $E_{\mathrm{c}}=1.5 \mathrm{MV} / \mathrm{m}$, polarization switching occurs near the IDE tip. It seems that the switching expands along the region near the interface between the PZT fiber and epoxy layer. The size of the $180^{\circ}$ switching zone increases with increasing electric field opposite to the original poling direction. The above numerical and experimental results show that if MFCs are operated under negative electric fields, the polarization switching effect is by no means negligible, and designers need to be aware of the nonlinear behavior. 


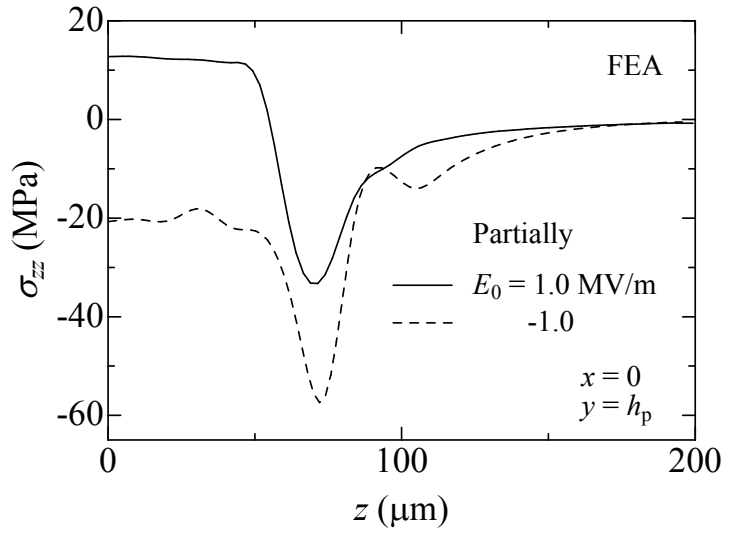

(a)

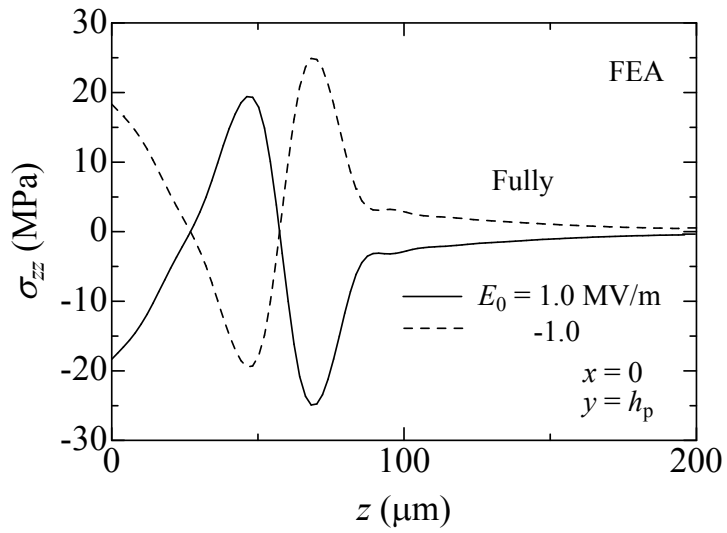

(b)

Figure 8. Variation of normal stress $\sigma_{z z}$ as a function of $z$ for MFCs with (a) partially and (b) fully poled PZT fibers; $x=0 \mathrm{~mm}$ and $y=h_{\mathrm{p}}$.

The normal stress $\sigma_{z z}$ as a function of $z$ at the $x=0 \mathrm{~mm}$ plane of the MFC with partially poled PZT fibers is shown in Figure $8 \mathrm{a}$ for $y=h_{\mathrm{p}}$ under an electric field $E_{0}= \pm 1.0 \mathrm{MV} / \mathrm{m}$. When a positive $E_{0}$ of $1.0 \mathrm{MV} / \mathrm{m}$ is applied, the normal stress in the neighborhood of the IDE tip changes from tensile to compressive and the maximum value of the compressive stress occurs at about $z=70 \mu \mathrm{m}$. It is interesting to note that under $E_{0}=-1.0 \mathrm{MV} / \mathrm{m}$, the highest compressive stress occurs at about $z=75 \mu \mathrm{m}$. Figure $8 \mathrm{~b}$ shows similar results for the MFC with fully poled PZT fibers. The maximum values of the compressive and tensile stresses occur under $E_{0}=1.0$ and $-1.0 \mathrm{MV} / \mathrm{m}$, respectively, at about $z=70 \mu \mathrm{m}$. Figure 9 shows the shear stress $\sigma_{y z}$ as a function of $z$ at the $x=0 \mathrm{~mm}$ plane of the MFCs with partially and fully poled PZT fibers for $y=h_{\mathrm{p}}$ under an electric field $E_{0}=1.0 \mathrm{MV} / \mathrm{m}$. The peak values of $\sigma_{y z}$ for the MFCs with partially and fully poled PZT fibers occur at different locations, and the maximum shear stress for the MFC with partially poled PZT fibers is larger than that for the MFC with fully poled PZT fibers. Figure 10 shows the normal stress $\sigma_{y y}$ as a function of $z$ at the $x=0 \mathrm{~mm}$ plane of the MFCs with

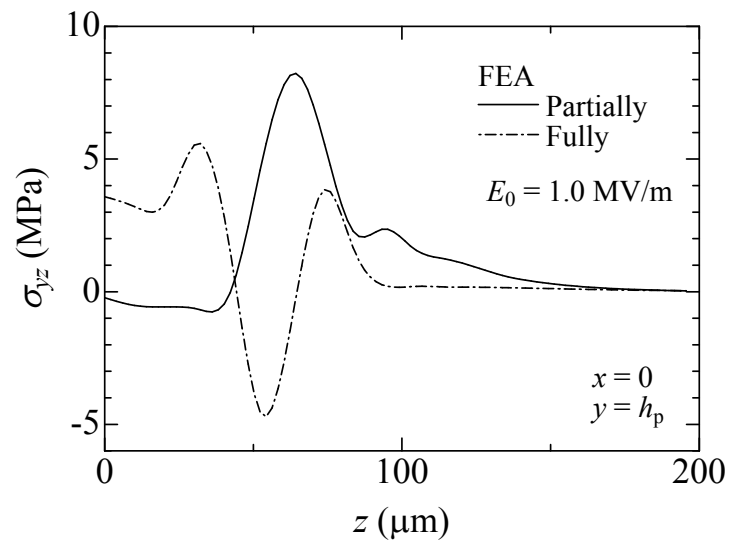

Figure 9. Variation of shear stress $\sigma_{y z}$ as a function of $z$ for MFCs with partially and fully poled PZT fibers; $x=0 \mathrm{~mm}$ and $y=h_{\mathrm{p}}$. 


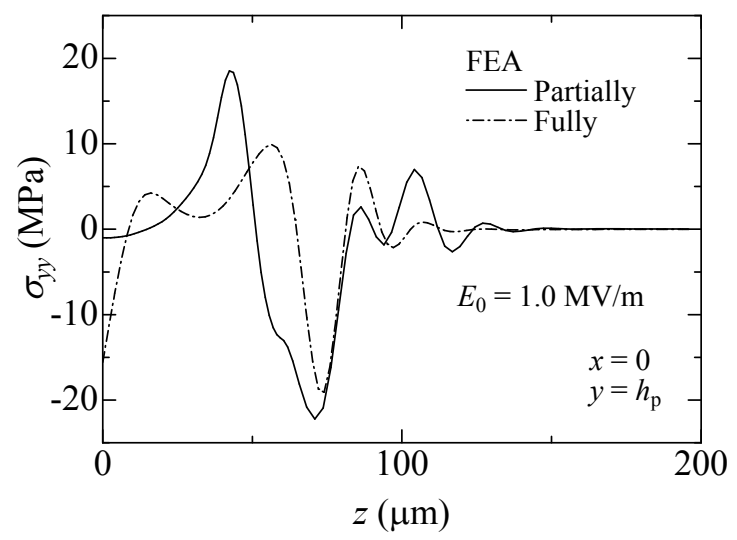

Figure 10. Variation of normal stress $\sigma_{y y}$ as a function of $z$ for MFCs with partially and fully poled PZT fibers; $x=0 \mathrm{~mm}$ and $y=h_{\mathrm{p}}$.

partially and fully poled PZT fibers for $y=h_{\mathrm{p}}$ under an electric field $E_{0}=1.0 \mathrm{MV} / \mathrm{m}$. The maximum value of the tensile stress for the MFC with partially poled PZT fibers is about twice that for the MFC with fully poled PZT fibers. A comparison between the results for MFCs with partially and fully poled PZT fibers indicates that the inhomogeneity near the IDE of the MFC has little effect on the strain versus electric field curve but affects the internal stresses.

\section{Conclusions}

This paper presents the results of numerical and experimental study in piezoelectric macrofiber composites (MFCs). The developed finite element model quantitatively predicted the strain versus electric field curve and captured the nonlinear electromechanical phenomena. We showed that the inhomogeneity near the interdigitated electrode (IDE) tip in the MFCs leads to dramatic differences in the internal stresses. By knowing how the partially poled lead zirconate titanate (PZT) fiber, IDE, and matrix constituents interact, we can design a MFC to achieve particular overall properties. The results of this study will help to offer a basis for optimizing piezoelectric MFC performance by selecting the optimal microstructure and properties of composite constituents.

\section{Appendix A}

For piezoelectric ceramics which exhibit hexagonal crystal symmetry of class $6 \mathrm{~mm}$ with respect to the principal $x_{1}, x_{2}$, and $x_{3}$ axes, the constitutive relations can be written in the form

$$
\left\{\begin{array}{l}
\sigma_{1} \\
\sigma_{2} \\
\sigma_{3} \\
\sigma_{4} \\
\sigma_{5} \\
\sigma_{6}
\end{array}\right\}=\left[\begin{array}{cccccc}
c_{11} & c_{12} & c_{13} & 0 & 0 & 0 \\
c_{12} & c_{11} & c_{13} & 0 & 0 & 0 \\
c_{13} & c_{13} & c_{33} & 0 & 0 & 0 \\
0 & 0 & 0 & c_{44} & 0 & 0 \\
0 & 0 & 0 & 0 & c_{44} & 0 \\
0 & 0 & 0 & 0 & 0 & c_{66}
\end{array}\right]\left\{\begin{array}{l}
\varepsilon_{1}-\varepsilon_{1}^{\mathrm{r}} \\
\varepsilon_{2}-\varepsilon_{2}^{\mathrm{r}} \\
\varepsilon_{3}-\varepsilon_{3}^{\mathrm{r}} \\
\varepsilon_{4}-\varepsilon_{4}^{\mathrm{r}} \\
\varepsilon_{5}-\varepsilon_{5}^{\mathrm{r}} \\
\varepsilon_{6}-\varepsilon_{6}^{\mathrm{r}}
\end{array}\right\}-\left[\begin{array}{ccc}
0 & 0 & e_{31} \\
0 & 0 & e_{31} \\
0 & 0 & e_{33} \\
0 & e_{15} & 0 \\
e_{15} & 0 & 0 \\
0 & 0 & 0
\end{array}\right]\left\{\begin{array}{l}
E_{1} \\
E_{2} \\
E_{3}
\end{array}\right\},
$$




$$
\left\{\begin{array}{l}
D_{1} \\
D_{2} \\
D_{3}
\end{array}\right\}=\left[\begin{array}{cccccc}
0 & 0 & 0 & 0 & e_{15} & 0 \\
0 & 0 & 0 & e_{15} & 0 & 0 \\
e_{31} & e_{31} & e_{33} & 0 & 0 & 0
\end{array}\right]\left\{\begin{array}{l}
\varepsilon_{1}-\varepsilon_{1}^{\mathrm{r}} \\
\varepsilon_{2}-\varepsilon_{2}^{\mathrm{r}} \\
\varepsilon_{3}-\varepsilon_{3}^{\mathrm{r}} \\
\varepsilon_{4}-\varepsilon_{4}^{\mathrm{r}} \\
\varepsilon_{5}-\varepsilon_{5}^{\mathrm{r}} \\
\varepsilon_{6}-\varepsilon_{6}^{\mathrm{r}}
\end{array}\right\}+\left[\begin{array}{ccc}
\epsilon_{11} & 0 & 0 \\
0 & \epsilon_{11} & 0 \\
0 & 0 & \epsilon_{33}
\end{array}\right]\left\{\begin{array}{l}
E_{1} \\
E_{2} \\
E_{3}
\end{array}\right\}+\left\{\begin{array}{l}
P_{1}^{r} \\
P_{2}^{r} \\
P_{3}^{r}
\end{array}\right\}
$$

where

$$
\begin{gathered}
\sigma_{1}=\sigma_{11}, \sigma_{2}=\sigma_{22}, \quad \sigma_{3}=\sigma_{33}, \quad \sigma_{4}=\sigma_{23}=\sigma_{32}, \quad \sigma_{5}=\sigma_{31}=\sigma_{13}, \quad \sigma_{6}=\sigma_{12}=\sigma_{21}, \\
\varepsilon_{1}=\varepsilon_{11}, \varepsilon_{2}=\varepsilon_{22}, \quad \varepsilon_{3}=\varepsilon_{33}, \quad \varepsilon_{4}=2 \varepsilon_{23}=2 \varepsilon_{32}, \quad \varepsilon_{5}=2 \varepsilon_{31}=2 \varepsilon_{13}, \quad \varepsilon_{6}=2 \varepsilon_{12}=2 \varepsilon_{21}, \\
\varepsilon_{1}^{\mathrm{r}}=\varepsilon_{11}^{\mathrm{r}}, \varepsilon_{2}^{\mathrm{r}}=\varepsilon_{22}^{\mathrm{r}}, \quad \varepsilon_{3}^{\mathrm{r}}=\varepsilon_{33}^{\mathrm{r}}, \varepsilon_{4}^{\mathrm{r}}=2 \varepsilon_{23}^{\mathrm{r}}=2 \varepsilon_{32}^{\mathrm{r}}, \quad \varepsilon_{5}^{\mathrm{r}}=2 \varepsilon_{31}^{\mathrm{r}}=2 \varepsilon_{13}^{\mathrm{r}}, \quad \varepsilon_{6}^{\mathrm{r}}=2 \varepsilon_{12}^{\mathrm{r}}=2 \varepsilon_{21}^{\mathrm{r}}, \\
c_{11}=c_{111}=c_{222}, c_{12}=c_{1122}, \quad c_{13}=c_{1133}=c_{2233}, c_{33}=c_{3333}, \\
c_{44}=c_{2323}=c_{3131}, c_{66}=c_{1212}=\frac{1}{2}\left(c_{11}-c_{12}\right), \\
e_{15}=e_{131}=e_{223}, \quad e_{31}=e_{311}=e_{322}, \quad e_{33}=e_{333} .
\end{gathered}
$$

The remanent strain and polarization are present in the piezoelectric material poled in the positive $x_{3}$-direction but because the remanent state is the reference for the measurement of strain and polarization, $\varepsilon_{i j}^{\mathrm{r}}$ and $P_{i}^{\mathrm{r}}$ are numerically equal to zero for the polarized state.

\section{Appendix B}

The values of $\Delta \varepsilon_{i j}=\varepsilon_{i j}^{\mathrm{r}}$ and $\Delta P_{i}=P_{i}^{\mathrm{r}}$ for $180^{\circ}$ switching can be expressed as

$$
\begin{gathered}
\Delta \varepsilon_{11}=0, \quad \Delta \varepsilon_{22}=0, \quad \Delta \varepsilon_{33}=0, \quad \Delta \varepsilon_{12}=0, \quad \Delta \varepsilon_{23}=0, \quad \Delta \varepsilon_{31}=0, \\
\Delta P_{1}=0, \quad \Delta P_{2}=0, \quad \Delta P_{3}=-2 P^{\mathrm{s}}
\end{gathered}
$$

For $90^{\circ}$ switching in the $x_{3} x_{1}$ plane, the changes are

$$
\begin{gathered}
\Delta \varepsilon_{11}=\gamma^{\mathrm{s}}, \quad \Delta \varepsilon_{22}=0, \quad \Delta \varepsilon_{33}=-\gamma^{\mathrm{s}}, \quad \Delta \varepsilon_{12}=0, \quad \Delta \varepsilon_{23}=0, \quad \Delta \varepsilon_{31}=0, \\
\Delta P_{1}= \pm P^{\mathrm{s}}, \quad \Delta P_{2}=0, \quad \Delta P_{3}=-P^{\mathrm{s}},
\end{gathered}
$$

where $\gamma^{\mathrm{s}}$ is a spontaneous strain. For $90^{\circ}$ switching in the $x_{2} x_{3}$ plane, we have

$$
\begin{gathered}
\Delta \varepsilon_{11}=0, \quad \Delta \varepsilon_{22}=\gamma^{\mathrm{s}}, \quad \Delta \varepsilon_{33}=-\gamma^{\mathrm{s}}, \quad \Delta \varepsilon_{12}=0, \quad \Delta \varepsilon_{23}=0, \quad \Delta \varepsilon_{31}=0, \\
\Delta P_{1}=0, \quad \Delta P_{2}= \pm P^{\mathrm{s}}, \quad \Delta P_{3}=-P^{\mathrm{s}} .
\end{gathered}
$$




\section{Appendix C}

The new piezoelectric constant $e_{i k l}^{\prime}$ is related to the elastic and direct piezoelectric constants by

$$
\begin{array}{llll}
e_{111}^{\prime}=d_{111}^{\prime} c_{11}+d_{122}^{\prime} c_{12}+d_{133}^{\prime} c_{13}, & e_{122}^{\prime}=d_{111}^{\prime} c_{12}+d_{122}^{\prime} c_{11}+d_{133}^{\prime} c_{13}, & \\
e_{133}^{\prime}=d_{111}^{\prime} c_{13}+d_{122}^{\prime} c_{13}+d_{133}^{\prime} c_{33}, & e_{123}^{\prime}=2 d_{123}^{\prime} c_{44}, \quad e_{131}^{\prime}=2 d_{131}^{\prime} c_{44}, & e_{112}^{\prime}=2 d_{112}^{\prime} c_{66}, \\
e_{211}^{\prime}=d_{211}^{\prime} c_{11}+d_{222}^{\prime} c_{12}+d_{233}^{\prime} c_{13}, & e_{222}^{\prime}=d_{211}^{\prime} c_{12}+d_{222}^{\prime} c_{11}+d_{233}^{\prime} c_{13}, & \\
e_{233}^{\prime}=d_{211}^{\prime} c_{13}+d_{222}^{\prime} c_{13}+d_{233}^{\prime} c_{33}, & e_{223}^{\prime}=2 d_{223}^{\prime} c_{44}, & e_{231}^{\prime}=2 d_{231}^{\prime} c_{44}, & e_{212}^{\prime}=2 d_{212}^{\prime} c_{66}, \\
e_{311}^{\prime}=d_{311}^{\prime} c_{11}+d_{322}^{\prime} c_{12}+d_{333}^{\prime} c_{13}, & e_{322}^{\prime}=d_{311}^{\prime} c_{12}+d_{322}^{\prime} c_{11}+d_{333}^{\prime} c_{13}, & \\
e_{333}^{\prime}=d_{311}^{\prime} c_{13}+d_{322}^{\prime} c_{13}+d_{333}^{\prime} c_{33}, & e_{323}^{\prime}=2 d_{323}^{\prime} c_{44}, & e_{331}^{\prime}=2 d_{331}^{\prime} c_{44}, & e_{312}^{\prime}=2 d_{312}^{\prime} c_{66} .
\end{array}
$$

The components of the piezoelectricity tensor $d_{i k l}^{\prime}$ are

$$
d_{i k l}^{\prime}=\left\{d_{333} n_{i} n_{k} n_{l}+d_{311}\left(n_{i} \delta_{k l}-n_{i} n_{k} n_{l}\right)+d_{131}\left(\delta_{i k} n_{l}-2 n_{i} n_{k} n_{l}+\delta_{i l} n_{k}\right)\right\},
$$

where $n_{i}$ is the unit vector in the poling direction, $\delta_{i j}$ is the Kronecker delta, $d_{333}=d_{33}, d_{311}=d_{31}$, and $d_{131}=d_{15} / 2$ are the direct piezoelectric constants, and

$$
d_{33}=\frac{\left(c_{11}+c_{12}\right) e_{33}-2 c_{13} e_{31}}{\left\{\left(c_{11}+c_{12}\right) c_{33}-2 c_{13}^{2}\right\}}, d_{31}=\frac{c_{33} e_{31}-c_{13} e_{33}}{\left\{\left(c_{11}+c_{12}\right) c_{33}-2 c_{13}^{2}\right\}}, d_{15}=\frac{e_{15}}{c_{44}} .
$$

\section{Appendix D}

$\operatorname{In}(8), e_{31}^{e}, e_{32}^{e}, e_{33}^{e}, s_{13}^{e}, s_{23}^{e}$, and $s_{33}^{e}$ are

$$
\begin{aligned}
e_{31}^{e} & =e_{31} \frac{c_{11 \mathrm{~m}} w_{\mathrm{p}} / W}{c_{11 \mathrm{~m}} w_{\mathrm{p}} / W+c_{11}\left(1-w_{\mathrm{p}} / W\right)}, \\
e_{32}^{e} & =e_{31}^{e} \frac{c_{11 \mathrm{~m}} w_{\mathrm{p}} / W+\left(c_{11}-c_{12}+c_{12 \mathrm{~m}}\right)\left(1-w_{\mathrm{p}} / W\right)}{c_{11 \mathrm{~m}}}, \\
e_{33}^{e} & =e_{33} w_{\mathrm{p}} / W+e_{31}^{e} \frac{\left(c_{12 \mathrm{~m}}-c_{13}\right)\left(1-w_{\mathrm{p}} / W\right)}{c_{11 \mathrm{~m}}}, \\
s_{13}^{e} & =\frac{C_{12} C_{23}-C_{13} C_{22}}{\left(C_{11} C_{22}-C_{12}^{2}\right) C_{33}-C_{11} C_{23}^{2}+2 C_{12} C_{13} C_{23}-C_{13}^{2} C_{22}}, \\
s_{23}^{e} & =\frac{C_{12} C_{13}-C_{11} C_{23}}{\left(C_{11} C_{22}-C_{12}^{2}\right) C_{33}-C_{11} C_{23}^{2}+2 C_{12} C_{13} C_{23}-C_{13}^{2} C_{22}}, \\
s_{33}^{e} & =\frac{C_{11} C_{22}-C_{22}^{2}}{\left(C_{11} C_{22}-C_{12}^{2}\right) C_{33}-C_{11} C_{23}^{2}+2 C_{12} C_{13} C_{23}-C_{13}^{2} C_{22}},
\end{aligned}
$$


where

$$
\begin{aligned}
& C_{11}=\frac{c_{11} c_{11 \mathrm{~m}}}{c_{11 \mathrm{~m}} w_{\mathrm{p}} / W+c_{11}\left(1-w_{\mathrm{p}} / W\right)}, \\
& C_{12}=\frac{c_{12} c_{11 \mathrm{~m}} w_{\mathrm{p}} / W+c_{11} c_{12 \mathrm{~m}}\left(1-w_{\mathrm{p}} / W\right)}{c_{11 \mathrm{~m}} w_{\mathrm{p}} / W+c_{11}\left(1-w_{\mathrm{p}} / W\right)}, \\
& C_{13}=\frac{c_{13} c_{11 \mathrm{~m}} w_{\mathrm{p}} / W+c_{11} c_{12 \mathrm{~m}}\left(1-w_{\mathrm{p}} / W\right)}{c_{11 \mathrm{~m}} w_{\mathrm{p}} / W+c_{11}\left(1-w_{\mathrm{p}} / W\right)}, \\
& C_{22}=c_{11} w_{\mathrm{p}} / W+c_{11 \mathrm{~m}}\left(1-w_{\mathrm{p}} / W\right)+\frac{C_{12}^{2}}{C_{11}}-\left\{\frac{c_{12}^{2} w_{\mathrm{p}} / W}{c_{11}}+\frac{c_{12 \mathrm{~m}}^{2}\left(1-w_{\mathrm{p}} / W\right)}{c_{11 \mathrm{~m}}}\right\}, \\
& C_{23}=c_{13} w_{\mathrm{p}} / W+c_{12 \mathrm{~m}}\left(1-w_{\mathrm{p}} / W\right)+\frac{C_{12} C_{13}}{C_{11}}-\left\{\frac{c_{12} c_{13} w_{\mathrm{p}} / W}{c_{11}}+\frac{c_{12 \mathrm{~m}}^{2}\left(1-w_{\mathrm{p}} / W\right)}{c_{11 \mathrm{~m}}}\right\}, \\
& C_{33}=c_{33} w_{\mathrm{p}} / W+c_{11 \mathrm{~m}}\left(1-w_{\mathrm{p}} / W\right)+\frac{C_{13}^{2}}{C_{11}}-\left\{\frac{c_{13}^{2} w_{\mathrm{p}} / W}{c_{11}}+\frac{c_{12 \mathrm{~m}}^{2}\left(1-w_{\mathrm{p}} / W\right)}{c_{11 \mathrm{~m}}}\right\},
\end{aligned}
$$

and

$$
c_{11 \mathrm{~m}}=\frac{E_{\mathrm{m}}\left(1-v_{\mathrm{m}}\right)}{\left(1+v_{\mathrm{m}}\right)\left(1-2 v_{\mathrm{m}}\right)}, \quad c_{12 \mathrm{~m}}=\frac{E_{\mathrm{m}} v_{\mathrm{m}}}{\left(1+v_{\mathrm{m}}\right)\left(1-2 v_{\mathrm{m}}\right)} .
$$

$E_{\mathrm{m}}$ and $v_{\mathrm{m}}$ in (D.13) are the Young's modulus and Poisson's ratio of the epoxy matrix.

\section{References}

[Bent and Hagood 1997] A. A. Bent and N. W. Hagood, "Piezoelectric fiber composites with interdigitated electrodes", J. Intell. Mater. Syst. Struct. 8:11 (1997), 903-919.

[Bilgen et al. 2010] O. Bilgen, A. Erturk, and D. J. Inman, "Analytical and experimental characterization of macro-fiber composite actuated thin clamped-free unimorph benders", J. Vib. Acoust. (ASME) 132:5 (2010), 051005.

[Brunner et al. 2009] A. J. Brunner, M. Birchmeier, M. M. Melnykowycz, and M. Barbezat, "Piezoelectric fiber composites as sensor elements for structural health monitoring and adaptive material systems", J. Intell. Mater. Syst. Struct. 20:9 (2009), $1045-1055$.

[Dano and Jullière 2007] M.-L. Dano and B. Jullière, "Active control of thermally induced distortion in composite structures using macro fiber composite actuators", Smart Mater. Struct. 16:6 (2007), 2315-2322.

[Dent et al. 2007] A. C. Dent, C. R. Bowen, R. Stevens, M. G. Cain, and M. Stewart, "Effective elastic properties for unpoled barium titanate", J. Eur. Ceram. Soc. 27:13-15 (2007), 3739-3743.

[Deraemaeker et al. 2009] A. Deraemaeker, H. Nasser, A. Benjeddou, and A. Preumont, "Mixing rules for the piezoelectric properties of macro fiber composites", J. Intell. Mater. Syst. Struct. 20:12 (2009), 1475-1482.

[Hayashi et al. 2003] K. Hayashi, Y. Shindo, and F. Narita, "Displacement and polarization switching properties of piezoelectric laminated actuators under bending", J. Appl. Phys. 94:7 (2003), 4603-4607.

[Hwang et al. 1995] S. C. Hwang, C. S. Lynch, and R. M. McMeeking, "Ferroelectric/ferroelastic interactions and a polarization switching model”, Acta Metall. Mater. 43:5 (1995), 2073-2084.

[Narita et al. 2007] F. Narita, Y. Shindo, and M. Mikami, "Electroelastic field concentrations and polarization switching induced by circular electrode at the interface of piezoelectric disk composites", Eur. J. Mech. A Solids 26:3 (2007), 394-404.

[Paradies and Melnykowycz 2007] R. Paradies and M. Melnykowycz, "Numerical stress investigation for piezoelectric elements with a circular cross section and interdigitated electrodes", J. Intell. Mater. Syst. Struct. 18:9 (2007), 963-972.

[Shindo et al. 2004] Y. Shindo, M. Yoshida, F. Narita, and K. Horiguchi, "Electroelastic field concentrations ahead of electrodes in multilayer piezoelectric actuators: experiment and finite element simulation", J. Mech. Phys. Solids 52:5 (2004), 1109-1124. 
[Shindo et al. 2009] Y. Shindo, F. Narita, and M. Hirama, "Electromechanical field concentrations near the electrode tip in partially poled multilayer piezo-film actuators”, Smart Mater. Struct. 18:8 (2009), 085020.

[Song et al. 2009] H. J. Song, Y.-T. Choi, A. S. Purekar, and N. M. Wereley, "Performance evaluation of multi-tier energy harvesters using macro-fiber composite patches”, J. Intell. Mater. Syst. Struct. 20:17 (2009), 2077-2088.

[Steinkopff 1999] T. Steinkopff, "Finite-element modelling of ferroic domain switching in piezoelectric ceramics", J. Eur. Ceram. Soc. 19:6-7 (1999), 1247-1249.

[Swain and Swain 1980] C. G. Swain and M. S. Swain, "A uniform random number generator that is reproducible, hardwareindependent, and fast”, J. Chem. Inf. Comput. Sci. 20:1 (1980), 56-58.

[Tan and Tong 2001] P. Tan and L. Tong, "Micro-electromechanics models for piezoelectric-fiber-reinforced composite materials", Compos. Sci. Technol. 61:5 (2001), 759-769.

[Williams et al. 2004] R. B. Williams, D. J. Inman, M. R. Schultz, M. W. Hyer, and W. K. Wilkie, "Nonlinear tensile and shear behavior of macro fiber composite actuators", J. Compos. Mater. 38:10 (2004), 855-869.

[Williams et al. 2006] R. B. Williams, D. J. Inman, and W. K. Wilkie, "Nonlinear response of the macro fiber composite actuator to monotonically increasing excitation voltage”, J. Intell. Mater. Syst. Struct. 17:7 (2006), 601-608.

Received 26 Jun 2010. Revised 10 Dec 2010. Accepted 13 Dec 2010.

YASUHIDE SHINDO: shindo@material.tohoku.ac.jp

Department of Materials Processing, Graduate School of Engineering, Tohoku University, Aoba-yama 6-6-02, Sendai 980-8579, Japan

FUMIO NARITA: narita@material.tohoku.ac.jp

Department of Materials Processing, Graduate School of Engineering, Tohoku University, Aoba-yama 6-6-02, Sendai 980-8579, Japan

Koji SATO: Department of Materials Processing, Graduate School of Engineering, Tohoku University, Aoba-yama 6-6-02, Sendai 980-8579, Japan

TOMO TAKEDA: takeda-t@material.tohoku.ac.jp

Department of Materials Processing, Graduate School of Engineering, Tohoku University, Aoba-yama 6-6-02, Sendai 980-8579, Japan 


\title{
JOURNAL OF MECHANICS OF MATERIALS AND STRUCTURES
}

\author{
jomms.org
}

Founded by Charles R. Steele and Marie-Louise Steele

EDITORS

Charles R. SteEle

DAVIDE BIGONI

Stanford University, USA

YASUHIDE SHINDO

University of Illinois at Urbana-Champaign, USA

Tohoku University, Japan

\section{EDITORIAL BOARD}

$\begin{aligned} \text { H. D. BUI } & \text { École Polytechnique, France } \\ \text { J. P. CARTER } & \text { University of Sydney, Australia } \\ \text { R. M. CHRISTENSEN } & \text { Stanford University, USA } \\ \text { G. M. L. GLADWELL } & \text { University of Waterloo, Canada } \\ \text { D. H. HODGES } & \text { Georgia Institute of Technology, USA } \\ \text { J. HUTCHINSON } & \text { Harvard University, USA } \\ \text { C. HWU } & \text { National Cheng Kung University, Taiwan } \\ \text { B. L. KARIHALOO } & \text { University of Wales, UK } \\ \text { Y. Y. KIM } & \text { Seoul National University, Republic of Korea } \\ \text { Z. MROZ } & \text { Academy of Science, Poland } \\ \text { D. PAMPLONA } & \text { Universidade Católica do Rio de Janeiro, Brazil } \\ \text { M. B. RUBIN } & \text { Technion, Haifa, Israel } \\ \text { A. N. SHUPIKOV } & \text { Ukrainian Academy of Sciences, Ukraine } \\ \text { T. TARNAI } & \text { University Budapest, Hungary } \\ \text { F. Y. M. WAN } & \text { University of California, Irvine, USA } \\ \text { P. WRIGGERS } & \text { Universität Hannover, Germany } \\ \text { W. YANG } & \text { Tsinghua University, China } \\ \text { F. ZIEGLER } & \text { Technische Universität Wien, Austria } \\ & \\ \text { PRODUCTION } & \text { contact@ msp.org } \\ \text { SILVIO LEVY } & \text { Scientific Editor }\end{aligned}$

Cover design: Alex Scorpan

Cover photo: Mando Gomez, www.mandolux.com

See http://jomms.org for submission guidelines.

JoMMS (ISSN 1559-3959) is published in 10 issues a year. The subscription price for 2011 is US \$520/year for the electronic version, and \$690/year (+\$60 shipping outside the US) for print and electronic. Subscriptions, requests for back issues, and changes of address should be sent to Mathematical Sciences Publishers, Department of Mathematics, University of California, Berkeley, CA 94720-3840.

JoMMS peer-review and production is managed by EditFLow ${ }^{\circledR}$ from Mathematical Sciences Publishers.

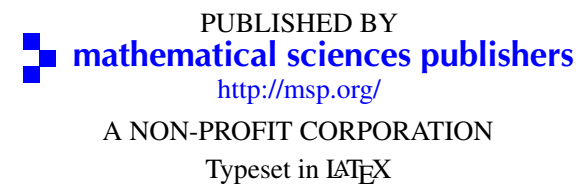

Copyright (C2011 by Mathematical Sciences Publishers 


\section{Journal of Mechanics of Materials and Structures}

\section{Volume 6, No. 7-8}

September-October 2011

\section{Special issue \\ Eleventh Pan-American Congress \\ of Applied Mechanics (PACAM XI)}

Preface

Adair R. Aguiar

949

Influence of specimen geometry on the Portevin-Le Châtelier effect due to dynamic strain aging

for the AA5083-H116 aluminum alloy

Rodrigo Nogueira de Codes and Ahmed Benallal

Dispersion relations for SH waves on a magnetoelectroelastic heterostructure with imperfect

interfaces

J. A. Otero, H. Calas, R. Rodríguez, J. Bravo, A. R. Aguiar and G. Monsivais

Numerical linear stability analysis of a thermocapillary-driven liquid bridge with magnetic stabilization

Yue Huang and Brent C. Houchens

Numerical investigation of director orientation and flow of nematic liquid crystals in a planar 1:4 expansion Pedro a. Cruz, Murilo F. Tomé, IAin W. Stewart and Sean McKee

Critical threshold and underlying dynamical phenomena in pedestrian-induced lateral vibrations of footbridges

Stefano LenCI and LAURA MARCHEgGiani

Free vibration of a simulation CANDU nuclear fuel bundle structure inside a tube

XUAN ZHANG and SHUdONG Yu

Nonlinear dynamics and sensitivity to imperfections in Augusti's model

D. Orlando, P. B. Gonçalves, G. Rega and S. LenCi

Active control of vortex-induced vibrations in offshore catenary risers: A nonlinear normal mode approach

CArlos E. N. MAZzilli and César T. SANCheS

Nonlinear electromechanical fields and localized polarization switching of piezoelectric macrofiber composites

Yasuhide Shindo, Fumio Narita, KoJi SATo and Tomo TAKeda

1089

Three-dimensional BEM analysis to assess delamination cracks between two transversely isotropic materials

Nicolás O. Larrosa, Jhonny E. Ortiz and Adrián P. Cisillino

Porcine dermis in uniaxial cyclic loading: Sample preparation, experimental results and modeling

A. E. Ehret, M. Hollenstein, E. MAzzA and M. Itskov

Analysis of nonstationary random processes using smooth decomposition

Rubens SAMpaio and Sergio Bellizzi

Perturbation stochastic finite element-based homogenization of polycrystalline materials

S. LePage, F. V. Stump, I. H. Kim and P. H. Geubelle

A collocation approach for spatial discretization of stochastic peridynamic modeling of fracture

Georgios I. Evangelatos and POL D. SPANOS 